\title{
A Comprehensive Assessment of Exposure and Vulnerabilities in Multi-Hazard Urban Environments: A Key Tool for Risk-Informed Planning Strategies
}

\author{
Adriana Galderisi (D) and Giada Limongi *(D) \\ Department of Architecture and Industrial Design, University of Campania "Luigi Vanvitelli", \\ 81100 Caserta, Italy; adriana.galderisi@unicampania.it \\ * Correspondence: giada.limongi@unicampania.it
}

check for updates

Citation: Galderisi, A.; Limongi, G. A Comprehensive Assessment of Exposure and Vulnerabilities in Multi-Hazard Urban Environments: A Key Tool for Risk-Informed Planning Strategies. Sustainability 2021, 13, 9055. http://doi.org/ $10.3390 /$ su13169055

Academic Editor:

Kalliopi Sapountzaki

Received: 28 June 2021

Accepted: 8 August 2021

Published: 12 August 2021

Publisher's Note: MDPI stays neutral with regard to jurisdictional claims in published maps and institutional affiliations.

Copyright: (c) 2021 by the authors. Licensee MDPI, Basel, Switzerland. This article is an open access article distributed under the terms and conditions of the Creative Commons Attribution (CC BY) license (https:/ / creativecommons.org/licenses/by/ $4.0 /)$.

\begin{abstract}
Although the increase in the frequency and intensity of disasters assigns a key role to disaster risk management in current debate on sustainable development, the efforts of national and local authorities to develop risk-informed planning strategies and increase disaster preparedness are still limited. In multi-hazard urban environments, the main criticality to support risk-informed planning strategies is the persisting lack of effective knowledge bases focused on the vulnerability of exposed assets to different hazards. Hence, this contribution, according to the first priority of the Sendai Framework for Disaster Risk Reduction—understanding disaster risk-and by tidying up methods and indicators developed in both EU research projects and scientific studies devoted to multirisk and vulnerability assessment, aims at better using available knowledge to guide risk-informed spatial planning. In detail, an indicator-based method to carry out a comprehensive exposure and vulnerability analysis has been outlined and tested on a case study area, the multi-hazard urban area of Campi Flegrei, located in the western part of the metropolitan city of Naples in the South of Italy. The proposed method may contribute to the building up of an effective risk knowledge base, enabling planners to easily access information on exposure and vulnerabilities to different hazards, and to differently combine them into output maps capable of supporting risk- informed planning strategies.
\end{abstract}

Keywords: exposure; vulnerability; systemic vulnerability; risk-sensitive spatial development; multi-risk

\section{Introduction}

Despite the emphasis put on disaster risk reduction (DRR) and climate change adaptation (CCA) in all recent documents on sustainable development, urban areas are still prone to the frequent impacts of individual or coupled hazards. Moreover, the constant growth of urban population and the increasing interconnectedness among urban elements and systems result in a growth of their exposure and vulnerability levels. Hence, it is urgent to develop risk reduction strategies, based on a multi-risk assessment capable of taking into account the different hazards potentially affecting a given area and their likely interactions, as well as the different assets exposed to each hazard and their multiple vulnerabilities.

The importance of a better understanding of disaster risk has been also remarked by the Sendai Framework 2015-2030 that assigned to risk knowledge a fundamental role to support all the phases of the disaster cycle. The document clearly outlines the key steps to improve risk knowledge, putting emphasis on the importance of consolidating the existing knowledge, of considering all risk components (hazard, exposure and vulnerabilities) and their potential interactions, of encouraging the use and strengthening of baselines at relevant spatial scales and their periodical updating as well as of ensuring an effective dissemination of such knowledge to different stakeholders. Moreover, the Sendai Framework underlines the importance of promoting comprehensive multi-risk analyses by taking into account climate change scenarios. 
However, even though over the past few decades, the relevance of multi-risk analyses has been largely recognized, this issue is still mostly confined to scientific debate, while current practices are often based on consolidated methods and procedures for single hazard/risk analyses [1-4].

The shift from risk to multi-risk assessment requires a radical change in perspective. While risk analysis has been for long "hazard-centered", starting from the characterization of individual hazards and their spatial distribution that leads to the identification of the potentially affected areas and elements at risk, multi-risk analysis should be "spatialcentered", starting from the selection of a geographical area in order to identify, firstly, the multiple hazards it is prone to and their potential interactions, and secondly, the exposed and vulnerable elements both to single hazards as well as to chained or coupled ones [5-8].

Comprehensive multi-risk analyses are paramount to support effective disaster risk reduction policies in existing urban areas, generally characterized as multi-hazard environments, with high levels of exposure and vulnerability, due to the constant growth of urban population and the increasing concentration of activities and assets. In these areas, risk-informed planning strategies, by acting on exposure and vulnerability features of urban areas to different hazards, could largely contribute to reduce current multi-risk levels, which are generally higher than risk levels measured in respect to individual hazards [5,6].

Nevertheless, even though the pivotal role of spatial planning for effective disaster risk reduction policies has been largely emphasized by numerous scholars and international documents on DRR, existing knowledge is often inadequate to support risk-informed planning strategies, which require detailed information on the vulnerabilities of exposed assets and systems $[3,9,10]$.

Based on these premises, this contribution is addressed to outline a methodological path to carry out a comprehensive exposure and vulnerability assessment in urban areas prone to multiple hazards as a first step towards a multi-risk analysis and aimed at supporting risk-informed planning strategies. In detail, Section 2 highlights the main gaps in currently available risk knowledge as well as the main outcomes of research works focused on multi-risk assessment; Section 3 outlines the key steps of the proposed methodological path; Section 4 provides an application of the methodological path on a multi-hazard urban environment, the Phlegraen Fields in the metropolitan area of Naples (Southern Italy); and Section 5 emphasizes the relevance of the proposed methodology for planning issues. The last Section 6 discusses the obtained results and offers some concluding remarks.

\section{Risk Knowledge: Current Gaps and Advances}

Despite the recognized importance of comprehensive multi-risk analyses to support effective DRR and CCA strategies, risk knowledge currently available still shows several shortcomings: fragmented knowledge bases developed by different authorities in charge of individual hazards; heterogeneous terminologies and methodologies for hazard and risk analysis; data and information provided at different geographical scales and not always up-to-date; frequent lack of in-depth vulnerability analyses as well as of adequate platforms to collect, synthesize and share existing data and information [11]. All these shortcomings hinder the possibility to effectively support risk-informed planning strategies: as the latter act on different spatial scales and according to different aims, they require both aggregate indexes to select the areas characterized by the highest multi-risk levels and disaggregate and detailed information on exposure and vulnerability at different scales to define adequate DRR strategies.

However, in the past decade, significant progress towards the development of comprehensive multi-risk analyses has been achieved, even if the increase in knowledge is not matched by its greater use in practice [12].

The topic of multi-risk analysis has been addressed by numerous scholars and European research projects, although according to different perspectives (e.g., na-tech events, simultaneous or cascading events, vulnerability to multi-hazard) $[13,14]$, and several review articles highlight the relevance of multi-risk in scientific literature and the different methods 
so far developed to improve risk knowledge in multi-hazard environments [3,4,6,13-15]. Most of the available methods can be traced back to two large groups: scenario techniques and indicator-based methods.

Some studies traceable to the first group have developed complex risk scenarios, based on site-specific hazard data and focused on selected chain of events and elementsat-risk $[16,17]$ : they clearly highlight how the interactions among different hazards may amplify the overall risk level in respect to the levels due to individual hazards. However, although very relevant to understand the complexity of chained events and urban systems as well as to define comprehensive risk indexes, they do not provide disaggregate data and information on the different risk components (exposure and vulnerability) useful to better guide risk-informed planning strategies.

Studies traceable to the second group have developed numerous sets of indicators aimed at providing a picture of the different risk components [18-21]. According to indicator-based methods, for instance, Kappes et al. [19], carried out a vulnerability assessment in multi-hazard contexts; Gallina et al. [22] developed a multi-vulnerability matrix, taking into account the physical and environmental vulnerability of different exposed targets prone to multiple climate-related hazards. However, these studies often fail in providing a comprehensive multi-risk assessment: focusing on specific "facets" of vulnerability; in fact, they generally overlook its multidimensional feature [23].

Nevertheless, indicator-based methods seem to be the most adequate to support risk-sensitive planning strategies [20,24]: they allow providing, without requiring massive data collection and elaboration or specific technical skills [22], both summary results and disaggregate information on individual risk components that are crucial, in turn, to support planning choices.

Therefore, with reference to an indicator-based method, this contribution aims at providing a methodological path to carry out a comprehensive analysis of exposure and vulnerability in urban areas prone to multiple hazards. In detail, the proposed path takes into account the multiple "facets" of vulnerability (physical, social, systemic) and allows building up a set of "spatialized" data and information, collected through open datasets, that can be combined into different output maps: from thematic maps, showing the vulnerability features of selected elements (e.g., residential buildings), to a comprehensive map, showing the overall levels of exposure and vulnerability of a given area in the face of multiple hazards. Thus, it provides a screening tool useful to prioritize the most vulnerable exposed areas and assets, but also to identify effective strategies to reduce their exposure and vulnerability levels.

\section{The Methodological Path}

As mentioned above, multi-risk analyses must be tailored to the context; thus, in this section, the main steps of the methodological path will be roughly presented to be then further detailed in respect to the selected case study (Section 4).

In order to carry out a comprehensive analysis of exposure and vulnerability of a selected area, two preliminary steps are required. First of all, available information related to the different hazards that the selected area is prone to have to be collected and codified. Secondly, the selected area has to be divided into homogeneous spatial units (HSUs), obtained through the overlapping into a GIS environment of three basic layers: minimum census units, as defined by the national census bureau, land uses (as defined by the Corine Land Cover) and hazard distribution. HSUs allow a "spatialization" of different data and information that, collected in respect to HSUs, can be then easily aggregated at different geographical scales.

\subsection{Exposure and Vulnerability Indicators}

Exposure levels of an urban system or of its partitions depend on the presence and consistency of "target elements"; that is, the elements that can be potentially affected by the hazards that a given area is prone to. Hence, their identification depends on the type 
of hazards affecting the selected area. Target elements can be articulated into two main categories: areal elements (e.g., residential areas, areas devoted to tertiary, commercial, tourist activities, etc.) and punctual elements (urban facilities, archaeological sites, industrial plants, etc.). These elements can be investigated through exposure indicators related to the distribution and density of areal elements or to the location and number of punctual elements.

Vulnerability has long been one of the most debated concepts in the field of DRR, and vulnerability analysis is nowadays considered crucial to both risk and multi-risk assessment: the development of effective disaster risk reduction strategies requires an in-depth knowledge of "who and what is most vulnerable" [25].

However, vulnerability is a multifaceted concept, referring to "the conditions determined by physical, social, economic and environmental factors or processes which increase the susceptibility of an individual, a community, assets or systems to the impacts of hazards" [26].

The diversity of the vulnerability facets is also mirrored by the heterogeneity of the available methods to analyze and assess it $[27,28]$, which range from fragility curves, to qualitative and quantitative indicators [20,29].

Among the several dimensions of vulnerability arising from European research projects [23] as well as from the numerous scientific articles that over the years have addressed vulnerability issues [30-33], we will focus here on three facets:

- Physical, which is the most investigated facet together with the social one; it is widely interpreted as the susceptibility of a given element/asset to be damaged (buildings, infrastructure, forests, etc.) [27,34].

- Social, which is generally related to the capacity of individuals and communities to cope with the adverse impacts of hazards [32,35].

- Systemic, the less investigated facet, which is typical of complex urban systems, since it mirrors the propensity of territorial elements to suffer damage (generally a functional damage) due to their linkages with other elements [36,37]; hence, this vulnerability facet is mostly related to the type of linkages among territorial elements, rather than to the hazard typology. Examples of systemic vulnerability are the failure of an electrical network that may induce cascading effects on several productive activities, or the permanent or temporary blockage of a road that may impede the accessibility of an emergency facility.

Despite being the least investigated facet of vulnerability, the concept of systemic vulnerability has been applied in several areas of natural hazards such as earthquakes, floods and volcanic eruptions [37-40] and it is nowadays considered as crucial to a better understanding of the overall vulnerability of urban systems. As a matter of fact, urban facilities and infrastructure play a crucial role for the "functioning" of urban systems both in peacetime and, even more, in case of a hazardous event, when their "malfunctioning" could induce a significant increase in the loss of lives and properties. These elements are numerous and diversified, ranging from hospitals and schools, to road and rail networks. In respect to these elements, it is important to analyse, besides their physical vulnerability, their susceptibility to suffer a reduction or even a loss of functionality due to their linkages with other elements of the urban system. The loss of functionality of a given element may influence, in fact, the functioning of the whole urban system, determining its failure in providing adequate responses in the aftermath of a hazardous event.

The focus on the three vulnerability facets is closely related to the adopted spatialplanning perspective. These facets are crucial indeed to support planning strategies aimed at recovering/regenerating existing urban areas, whereas they also provide useful insights for emergency management. For instance, physical vulnerability is paramount to support retrofitting strategies, while social vulnerability indicators may be very useful to better drive regeneration strategies at neighborhood or municipal scale. Moreover, systemic vulnerability indicators, by identifying the main shortcomings of urban facilities, strategic equipment and/or infrastructure, can support strategic plans at a metropolitan or regional 
scale towards the relocation of urban facilities or strategic equipment as well as towards the strengthening of the mobility networks.

Thus, the assessment of the vulnerabilities of exposed targets through qualitativequantitative indicators allows:

- Characterizing some relevant aspects of exposed elements or systems through simple indicators or through their combinations into compound indicators;

- Replicating the analysis by adapting the set of indicators to different contexts and at different scales, by easily comparing different urban areas or territorial systems.

The set of vulnerability indicators can be outlined based on some European research projects and scientific articles (Table 1) that over the years have provided methods and tools to assess vulnerabilities both in a single-risk and in a multi-risk perspective.

Table 1. Main references for the selection of indicators.

\begin{tabular}{|c|c|}
\hline EU Projects & Vulnerability Facets \\
\hline $\begin{array}{c}\text { ARMONIA } \\
2004-2007\end{array}$ & $\begin{array}{l}\text { physical v. } \\
\text { social } v . \\
\text { systemic } v .\end{array}$ \\
\hline $\begin{array}{l}\text { ENSURE } \\
2008-2011\end{array}$ & $\begin{array}{l}\text { physical } v . \\
\text { social v. } \\
\text { systemic } v .\end{array}$ \\
\hline $\begin{array}{c}\text { MOVE } \\
2008-2011\end{array}$ & $\begin{array}{l}\text { physical } v . \\
\text { social v. } \\
\text { systemic } v .\end{array}$ \\
\hline $\begin{array}{c}\text { RESIN } \\
\text { 2015-2018 }\end{array}$ & $\begin{array}{l}\text { physical v. } \\
\text { social } v . \\
\text { systemic } v .\end{array}$ \\
\hline References & Vulnerability facets \\
\hline Cutter et al., 2008 & social $v$. \\
\hline Barbat et al., 2010 & physical v. \\
\hline Kappes et al., 2012 & physical v. \\
\hline Tilio et al., 2012 & systemic v. \\
\hline Welle et al., 2013 & social $v$. \\
\hline Scaini et al., 2014 & systemic v. \\
\hline Aliabadi et al., 2015 & $\begin{array}{l}\text { physical } v . \\
\text { social } v . \\
\text { systemic } v .\end{array}$ \\
\hline Khademi et al., 2015 & systemic $v$. \\
\hline Papathoma-Köhle et al., 2017 & physical v. \\
\hline Elboshy et al., 2019 & $\begin{array}{l}\text { physical } v . \\
\text { social v. } \\
\text { systemic } v .\end{array}$ \\
\hline
\end{tabular}

In detail, several indicators aimed at assessing physical vulnerability of built environment in the face of natural hazards $[27,34,41,42]$ have been so far defined in the field of engineering studies; they generally refer to the structural features of buildings as well as to their maintenance (e.g., construction typologies, age of buildings, conservation degree) [43]. More recently, some indicators related to the physical vulnerability of the built environment to climate related hazards (e.g., floods, heat waves) have been also developed, such as the imperviousness of the urban fabrics' surfaces and the vegetation index [44].

Available indicators useful to characterize social vulnerability generally include population structure, such as the old-age index, the percentage of elderly and children compared 
to the resident population, which allows defining a dependency ratio and the difficulty of autonomous travel in case of evacuations; the education rate and presence of social marginalization; and employment levels, which affect the capacity of individuals to cope with hazards' impacts [45].

Indicators related to systemic vulnerability generally refer to the type of available urban facilities and infrastructure, to their functional role/relevance in a given context as well as to their redundancy. In particular, available studies on systemic vulnerability often refer to the redundancy of territorial facilities, to the accessibility levels of the different areas/facilities as well as to the redundancy and connectivity of the transport networks $[46,47]$.

\subsection{From the Selection of Indicators to the Output Maps}

Once the set of indicators has been selected, each indicator can be measured through data collected from different datasets. The raw data deriving from the available datasets have to be associated to the different HSUs and to the specific indicator, homogenized and normalized according to a common scale of values [10]. It is worth pointing out that while exposure, physical and social vulnerability indicators can be measured through a "soft" reprocessing of data extracted from existing databases (e.g., National Census, Copernicus layers), systemic vulnerability indicators require more in-depth analyses of features and functional roles of urban and emergency facilities as well as of road and railway networks, that, however, can be obtained thanks to GIS tools and do not require in situ surveys.

Then, as for hazards, all the selected exposure and vulnerability indicators require a coding process, in order to combine them into a comprehensive exposure and vulnerability assessment. Moreover, due to the heterogeneity of the collected data, all exposure and vulnerability indicators can be homogenized and normalized in a range from 0 to 1 , according to the formulas:

$$
\begin{gathered}
e_{x, y, z}^{\prime}=\left(e_{x, y, z}-e_{x, y, z, \min }\right) /\left(e_{x, y, z, \max }-e_{x, y, z, \min }\right) \\
v_{x, y, w}^{\prime}=\left(v_{x, y, w}-v_{x, y, w, \min }\right) /\left(v_{x, y, w, \max }-v_{x, y, w, \min }\right)
\end{gathered}
$$

where:

- $e_{x, y, z}$ is the not homogeneous exposure level of exposure indicator $z$ attributed to the element $y$;

- $\quad v_{x, y, w}$ is the not homogeneous vulnerability level of vulnerability indicator $w$ attributed to the element $y$.

The main output of this process is represented by single homogenized maps where each HSU is related to values of $e^{\prime}, v^{\prime}$ ranging from 0 to 1 . Then, in order to switch from a collection of maps related to each homogenized indicator to a comprehensive exposure and vulnerability map, the different indicators can be combined with each other. In detail, exposure and vulnerability values, calculated in respect to each hazard, can be combined to obtain a total exposure value multiplied by vulnerability values:

$$
V E_{x}=\sum e_{x, y, z}^{\prime}\left(v_{x, y, 1}^{\prime}+v_{x, y, 2}^{\prime}+\ldots+v_{x, y, n}\right)
$$

where the total value VE of a given area to the hazard $(x)$ is given by the sum of each exposure indicator $(z)$ multiplied by the sum of the vulnerability indicator values $(n)$.

This step allows obtaining two main outputs:

- Single maps showing the distribution of exposure and vulnerability levels (EV Map), in respect to the hazard $(x)$, for each class of exposed element;

- $\quad$ Single maps showing the distribution of exposure and vulnerability levels (EV Map) in respect to the hazard $(x)$, with a scale normalized on the worst case (maximum value of $V E_{x, y}$ ) (Figure 1). 


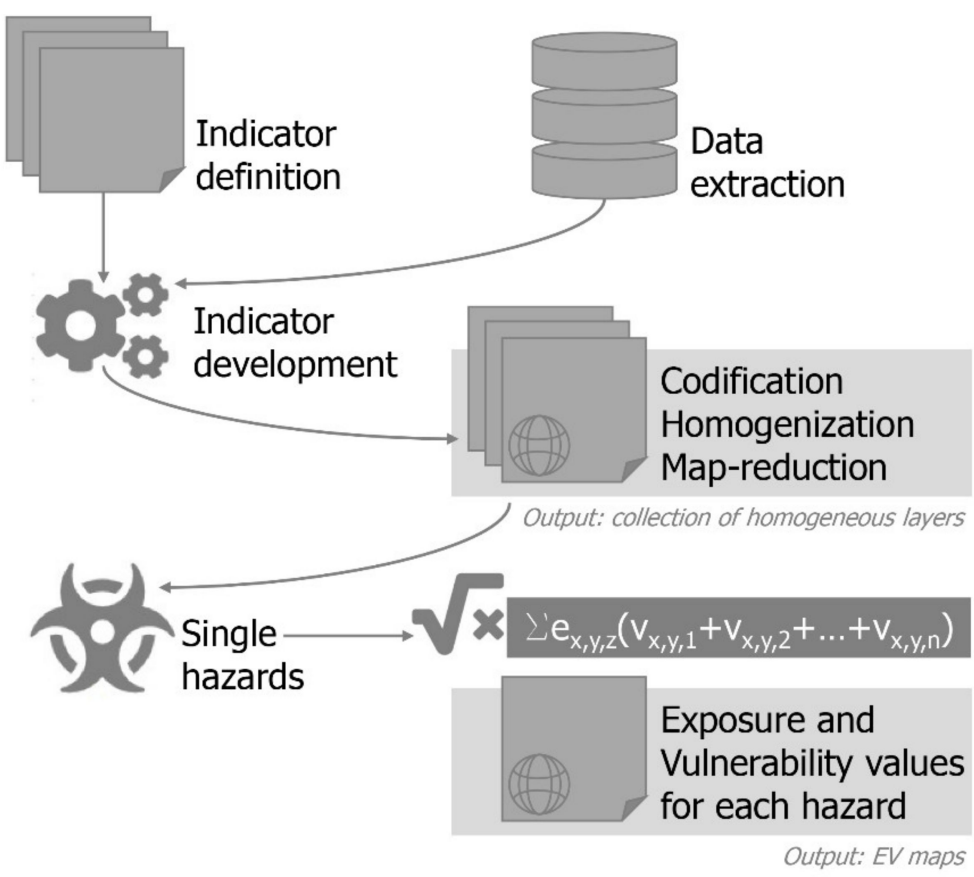

Figure 1. The process from data extraction to the output maps.

These maps can be obtained by multiplying exposure levels with the sum of vulnerability indicators' values attributed to each class of exposed elements, or by considering the total exposure value with its vulnerability value for each hazard following the Formula (3).

Finally, besides the EV maps related to each hazard, it is possible to carry out a comprehensive EV map, which provides a summary value of exposure and vulnerability levels of each HSU in respect to all hazards affecting the case study area. To this aim, the selected indicators have to be hierarchically ordered [19]. Such a hierarchy can be defined only in respect to a selected case study area, since it depends on the relevance of each indicator to each considered hazards. In detail, an indicator that is significant for all the considered hazards will have a greater weight than an indicator exclusively referred to a single hazard. Hence, physical vulnerability indicators, which generally refer to individual hazards (seismic, landslides, etc.) will generally have a lower weight in respect to other indicators, such as social (e.g., population age) or systemic vulnerability indicators (e.g., accessibility), which refer to multiple hazards.

Following this approach, the formula (3) can be redefined as follows:

$$
V E=\sum e_{x, y, z}\left(\sum w v\right)
$$

where $w$ is the weight assumed by each vulnerability indicator, according to its relevance in respect to each hazard. Such relevance has been defined according to the selected scientific literature - that generally provides vulnerability indicators in respect to specific hazards-and measured according to a binary approach (yes/no).

\section{The Case Study Area: A Multi-Hazard Urban Environment in Southern Italy}

The case study area-the Phlegraean Fields, located in the western part of the metropolitan city of Naples, in Southern Italy (Figure 2)-represents a paradigmatic example of a multi-hazard urban environment: in addition to the volcanic hazards, this area is prone to several natural and man-made hazards and is characterized by a high population density and a relevant historical, archaeological and natural heritage. Moreover, it is worth noting that, compared to other volcanic areas characterized by a central volcanic system, such as the Vesuvian area, in the Phlegraean Fields, the area of possible opening of eruptive vents is very large, with significant consequences in terms of extension of the potentially affected territory [48]. 

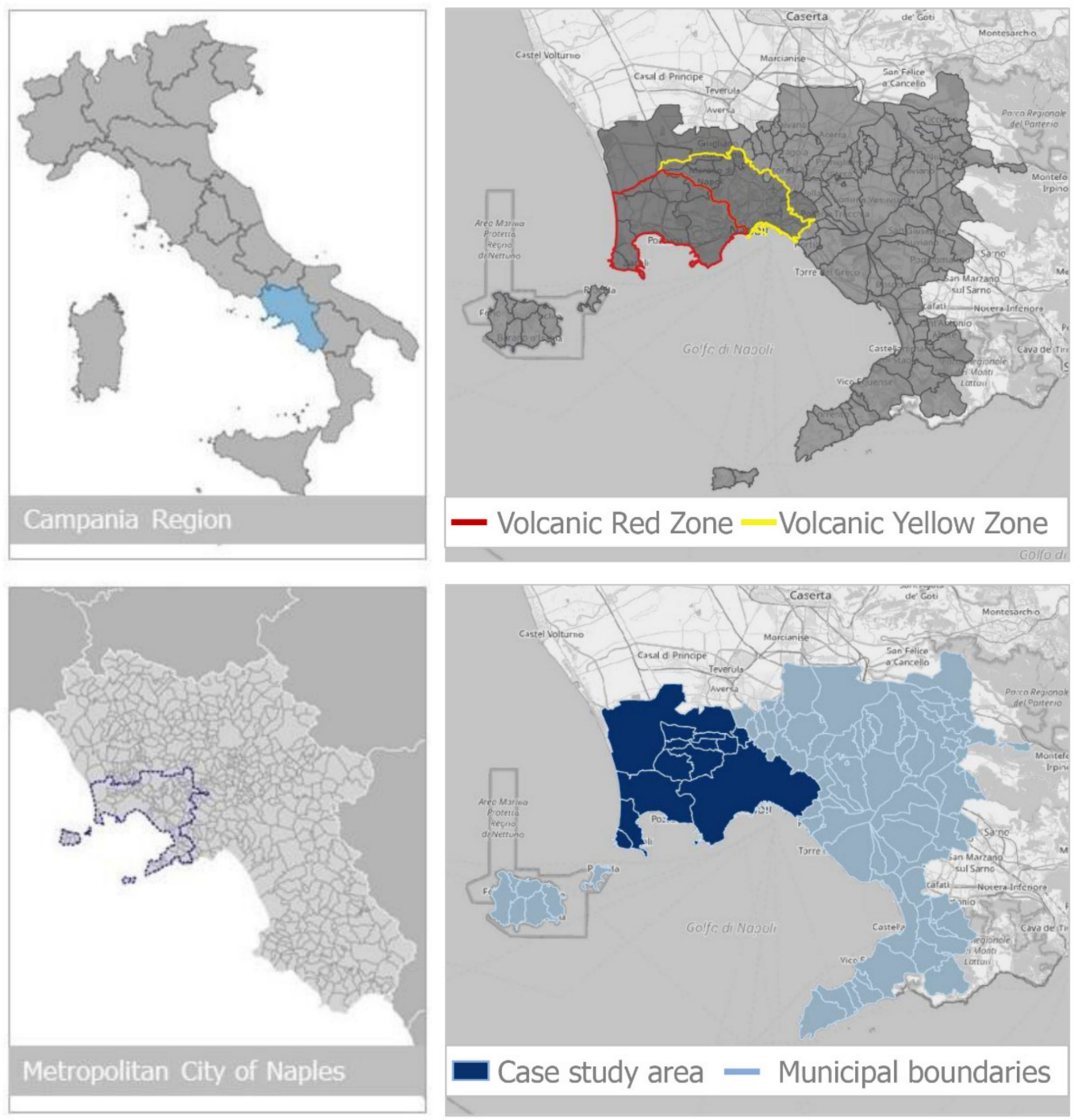

Figure 2. The case study area.

The selected case study area includes twelve municipalities: four of them are entirely included in the "red zone" of the Phlegraean Fields, which is classified as the highest risk area; the others are partially included in the red zone or included in the "yellow zone" (including part of the capital city of the Metropolitan area, that is the City of Naples), classified as areas at medium risk. Only one of the selected municipalities is not included in the volcanic area of the Phlegraean Fields: the Municipality of Qualiano. Nevertheless, the latter has been included in the case study area since, although not affected by volcanic hazard, it is enclosed between two municipalities partially included in the volcanic zone: Giuliano in Campania, partially included in the red zone, and Villaricca, which is part of the yellow zone.

Besides volcanic hazards, the case study area is also prone to other hazards, namely earthquakes, since all the selected municipalities are classified as areas at medium-high seismicity (corresponding to the seismic zone 2 ), landslides (10\% of the overall territorial surface) and hydraulic hazard ( $10 \%$ of the overall surface). Moreover, the case study area hosts numerous hazardous industrial plants: $40 \%$ of the total hazardous industrial plants of the Metropolitan City of Naples are located in the case study area.

The twelve selected municipalities host more than 1,400,000 inhabitants (ISTAT 2019), which is about half of the inhabitants of the Metropolitan City of Naples, made up of 92 municipalities. 
Once the case study area has been identified, all the available information on the different hazards that this area is prone to have been collected.

In particular, the case study area is prone to different sudden-onset hazards that, according to the terminology reported in numerous international documents (Hyogo framework, Sendai Framework, UNISDR Glossary 2004, 2016), can be classified as follows: geophysical hazards, whose origin is purely natural; hydrometeorological hazards, whose origin is however natural, but altered in different ways by anthropogenic pressures; anthropogenic hazards, such as industrial accidents, whose origin is purely anthropic (Table 2). Table 2 also shows the codes assigned to each hazard. The coding process is also adopted to identify the classes of elements at risk and the exposure and vulnerability indicators in order to combine all the data into the comprehensive exposure and vulnerability assessment.

Table 2. Considered typologies of hazards and codes.

\begin{tabular}{lc}
\hline Geological and Geophysical & Code \\
\hline Earthquakes & $\mathrm{Eq}$ \\
Volcanic Eruptions & $\mathrm{LF}$ \\
$\quad$ lava flows & $\mathrm{PF}$ \\
pyroclastic flows & $\mathrm{As}$ \\
$\quad$ ashes & $\mathrm{La}$ \\
Landslides & \\
\hline Hydrometeorological & $\mathrm{Fl}$ \\
\hline Floods & $\mathrm{HW}$ \\
\hline Extreme temperatures (heat waves) & \\
\hline Anthropogenic & $\mathrm{IA}$ \\
\hline Industrial accidents & \\
\hline
\end{tabular}

Then, the whole area has been preliminarily divided into homogeneous spatial units (HSUs), obtained through the overlapping into a GIS environment of census units provided by the Italian Institute of Statistics (ISTAT), Corine Land Cover areas and hazard levels, namely hydraulic and landslide hazard levels and volcanic classification, being the whole territory included in the same seismic zone (zone 2), according to the national seismic classification issued in April 2021 (Figure 3).
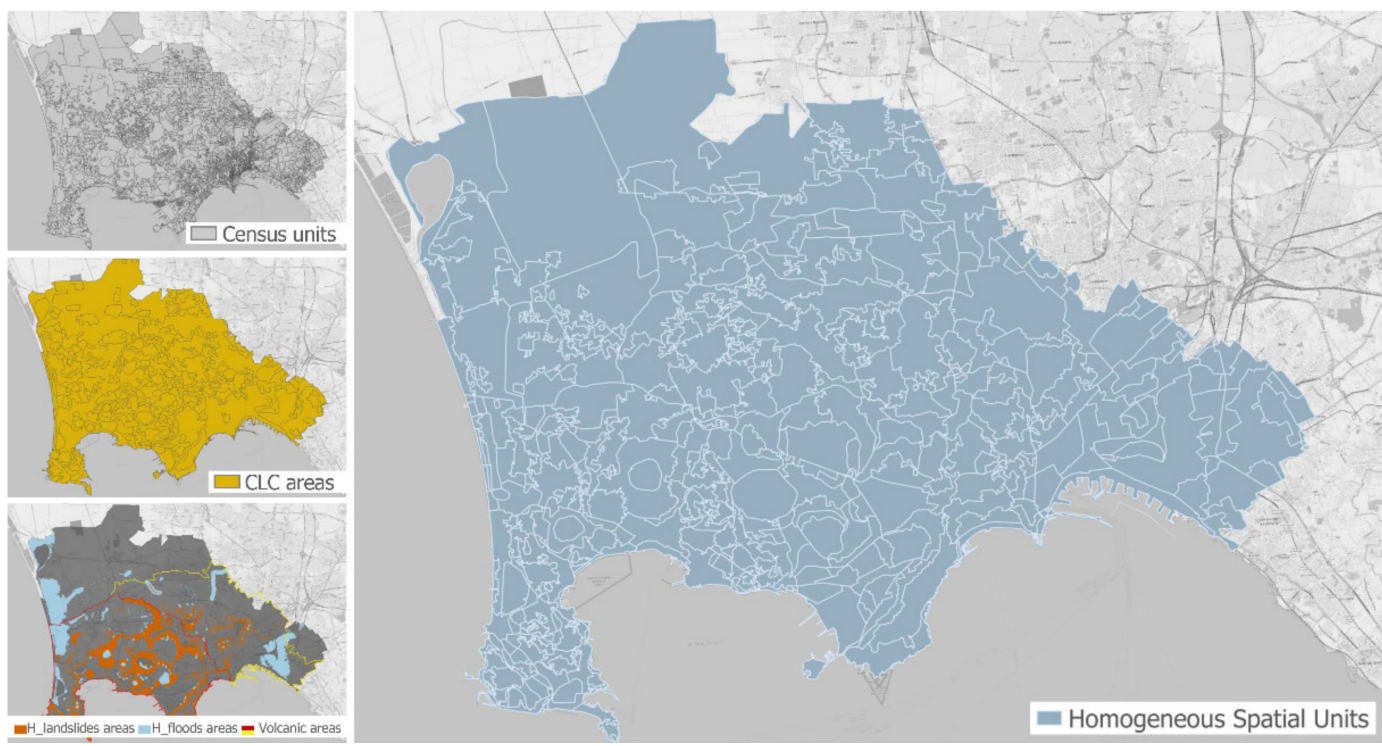

Figure 3. The case study areas divided into HSUs. 
Then, according to the hazard features of the case study area, exposed targets have been identified and classified and, for each class of exposed elements, exposure and vulnerability indicators have been selected, based on the references provided in Table 1. The selected set of indicators (Table 3 ) is composed of:

- Indicators deriving from standard datasets (e.g., National Statistics, Copernicus) already available and spatialized, which only need to be systematized and homogenized. They can be easily reprocessed according to the different goals and scaled to different spatial units.

- Specific indicators referable to specific hazards or spatial scales that must be identified through devoted analysis (focus).

Table 3. Selected exposure and vulnerability indicators.

\begin{tabular}{|c|c|c|c|c|}
\hline $\begin{array}{l}\text { Classes of Exposed } \\
\text { Elements }\end{array}$ & Exposure Indicators & $\begin{array}{l}\text { Vulnerability } \\
\text { Indicators }\end{array}$ & $\begin{array}{l}\text { Vulnerability } \\
\text { Dimensions }\end{array}$ & Data Sources \\
\hline \multirow{9}{*}{ Residential areas } & \multirow{9}{*}{$\begin{array}{l}\mathrm{n}^{\circ} \text { of residential } \\
\text { buildings/total }\end{array}$} & Utilization degree & Physical & National Census \\
\hline & & Urban density & Physical & Copernicus HRL \\
\hline & & Construction type & Physical & National Census \\
\hline & & Imperviousness & Physical & Copernicus HRL \\
\hline & & Vegetation index & Physical & Copernicus HRL \\
\hline & & Conservation degree & Physical & National Census \\
\hline & & Age of buildings & Physical & National Census \\
\hline & & Buildings' material & Physical & National Census \\
\hline & & $\begin{array}{c}\text { Number of } \\
\text { storeys(height value) }\end{array}$ & Physical & National Census \\
\hline \multirow{5}{*}{$\begin{array}{c}\text { Commercial, touristic, } \\
\text { tertiary areas }\end{array}$} & \multirow{5}{*}{$\begin{array}{c}\mathrm{n}^{\circ} \text { of non-residential } \\
\text { buildings/total }\end{array}$} & Utilization degree & Physical & National Census \\
\hline & & Urban density & Physical & Copernicus HRL \\
\hline & & Construction type & Physical & National Census \\
\hline & & Imperviousness & Physical & Copernicus HRL \\
\hline & & Vegetation index & Physical & Copernicus HRL \\
\hline \multirow{4}{*}{ Urban Facilities } & \multirow{4}{*}{$\mathrm{n}^{\circ}$ of buildings or areas } & Hierarchical level & Systemic & Focus \\
\hline & & Strategic role & Systemic & Focus \\
\hline & & Accessibility & Systemic & Focus \\
\hline & & Redundancy & Systemic & Focus \\
\hline \multirow{4}{*}{$\begin{array}{l}\text { Historical and cultural } \\
\text { heritage }\end{array}$} & \multirow{4}{*}{$\mathrm{n}^{\circ}$ of building or site } & Construction type & Physical & MiBACT database \\
\hline & & Imperviousness & Physical & Copernicus HRL \\
\hline & & Vegetation index & Physical & Copernicus HRL \\
\hline & & Cultural value & Systemic & MiBACT database \\
\hline \multirow{6}{*}{$\begin{array}{l}\text { Transport } \\
\text { infrastructure }\end{array}$} & length of roads & Hierarchical level & Systemic & Focus \\
\hline & road access & $\begin{array}{l}\text { Presence of bridges, } \\
\text { tunnels or underpasses }\end{array}$ & Physical & OpenStreetMap \\
\hline & & Imperviousness & Physical & Copernicus HRL \\
\hline & length of railways & Strategic role & Systemic & Focus \\
\hline & & Connectivity & Systemic & Focus \\
\hline & $\mathrm{n}$ of railway stations & Redundancy & Systemic & Focus \\
\hline \multirow[b]{2}{*}{ Industrial sites } & \multirow[b]{2}{*}{$\mathrm{n}^{\circ}$ of sites } & Type of production & Physical & Regional registers \\
\hline & & $\begin{array}{c}\text { residential/natural } \\
\text { areas }\end{array}$ & Physical & Focus \\
\hline \multirow{5}{*}{ Population } & \multirow{5}{*}{ population density } & Age-old age index & Social & National Census \\
\hline & & Education & Social & National Census \\
\hline & & Employment & Social & National Census \\
\hline & & $\begin{array}{l}\text { Autonomy-\% } \\
\text { children and elderly }\end{array}$ & Social & National Census \\
\hline & & $\begin{array}{l}\text { Immigrants and } \\
\text { refugees }\end{array}$ & Social & National Census \\
\hline
\end{tabular}


The selected exposure and vulnerability indicators have been measured based on three main sources:

- The census data provided by the Italian Institute of Statistic (ISTAT). The national census provides, for each census unit, data on population (age, education, employment, etc.) and building stock (occupied or empty dwellings, age of buildings, etc.). Even though some census data at the municipal scale are permanently updated, data provided for individual census units are available only in respect to the last census, which dates to 2011.

- The Corine Land Cover layer released by Copernicus and updated to 2018, together with the Urban Atlas layer and the High-Resolution Layers, which provide useful data related to both imperviousness and tree cover density.

- The Open Street Map layers updated to 2020, integrated with other sources such as the Geonational web-GIS for information on educational facilities, the portal of the Ministry of Cultural Heritage (MiBACT) for the information on cultural heritage, the regional technical maps for the location and features of the transport network.

The raw data derived from these datasets have been associated with the HSUs previously identified and subsequently processed as exposure or vulnerability indicators.

All exposure and vulnerability indicators have been homogenized and normalized in a range from 0 to 1, according to the Formulas (1) and (2) (see Section 3).

The outputs of this process are single homogenized maps related to each selected indicator: in these maps, HSUs are ranked through normalized values of $e^{\prime}, v^{\prime}$ ranging from 0 to 1 (Figures 4 and 5).

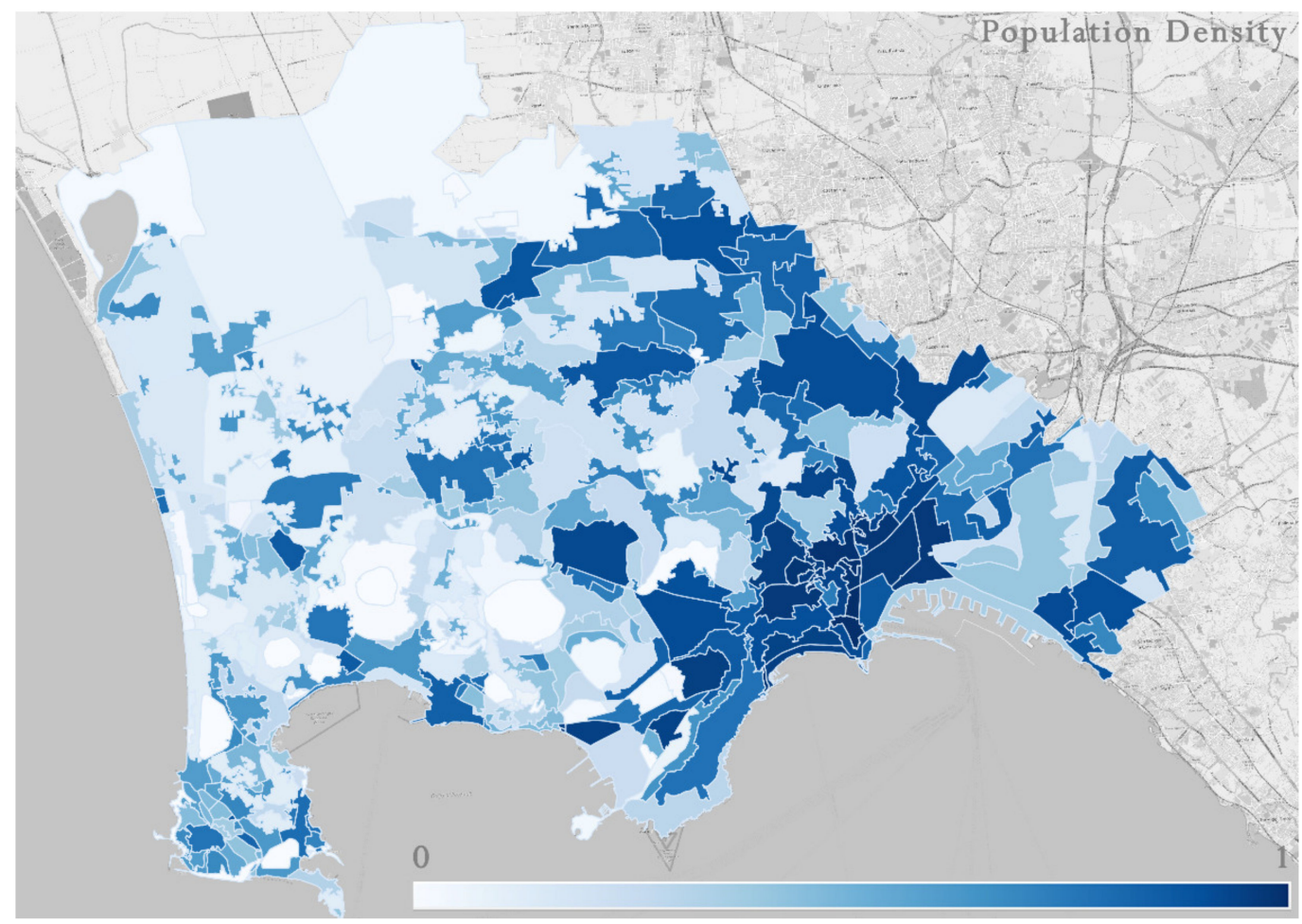

Figure 4. Maps of exposure and vulnerability: population density (exposure). 


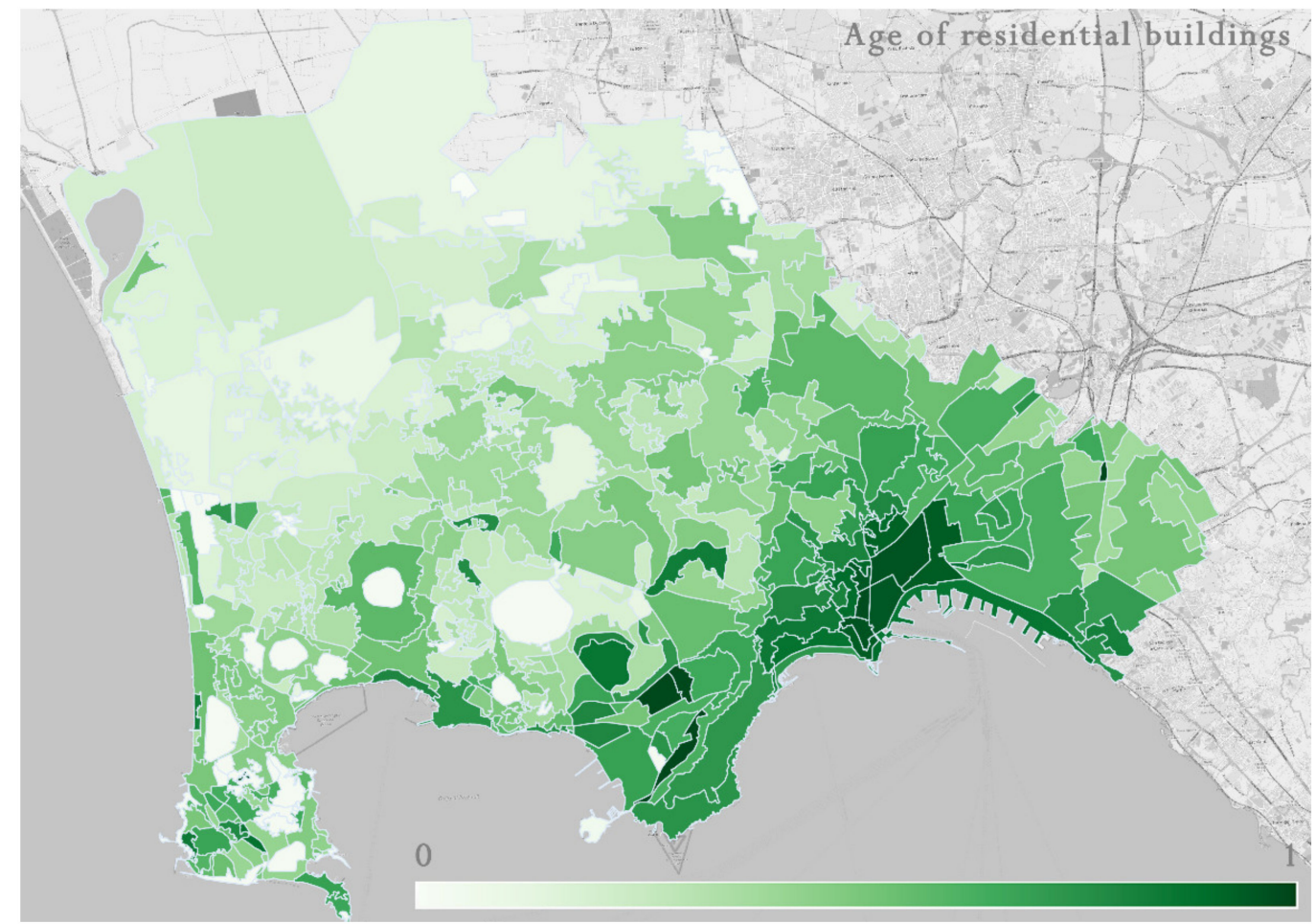

Figure 5. Maps of exposure and vulnerability: age of residential buildings (physical vulnerability).

Then, following the formula (3) (see Section 3), it is possible to carry out single EV maps for each class of exposed element in respect to each considered hazard. Figures 6 and 7 show the EV maps for residential areas and cultural heritage in the face of seismic hazard, respectively.

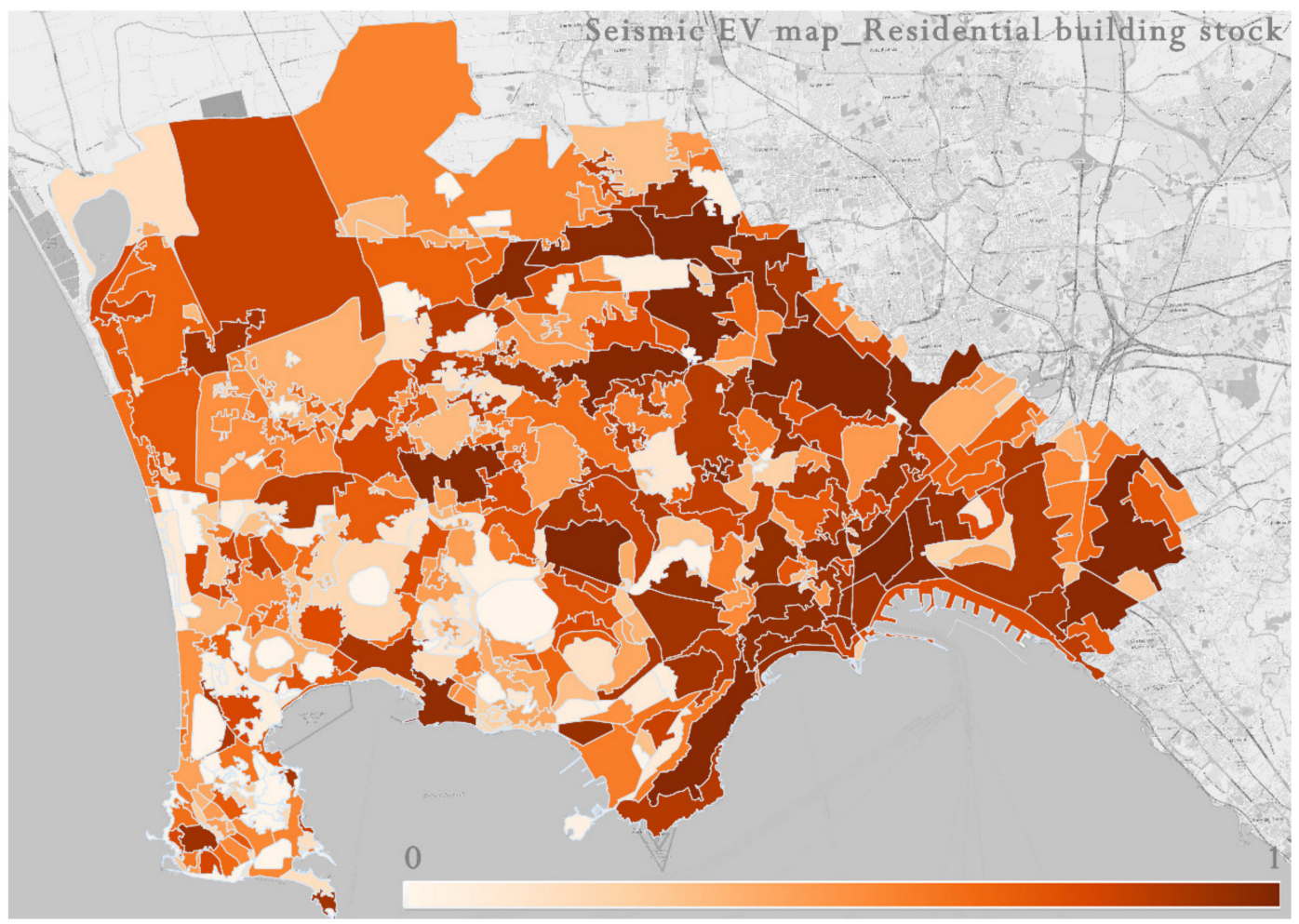

Figure 6. Exposure and vulnerability levels of residential building stock in the face of earthquakes. 


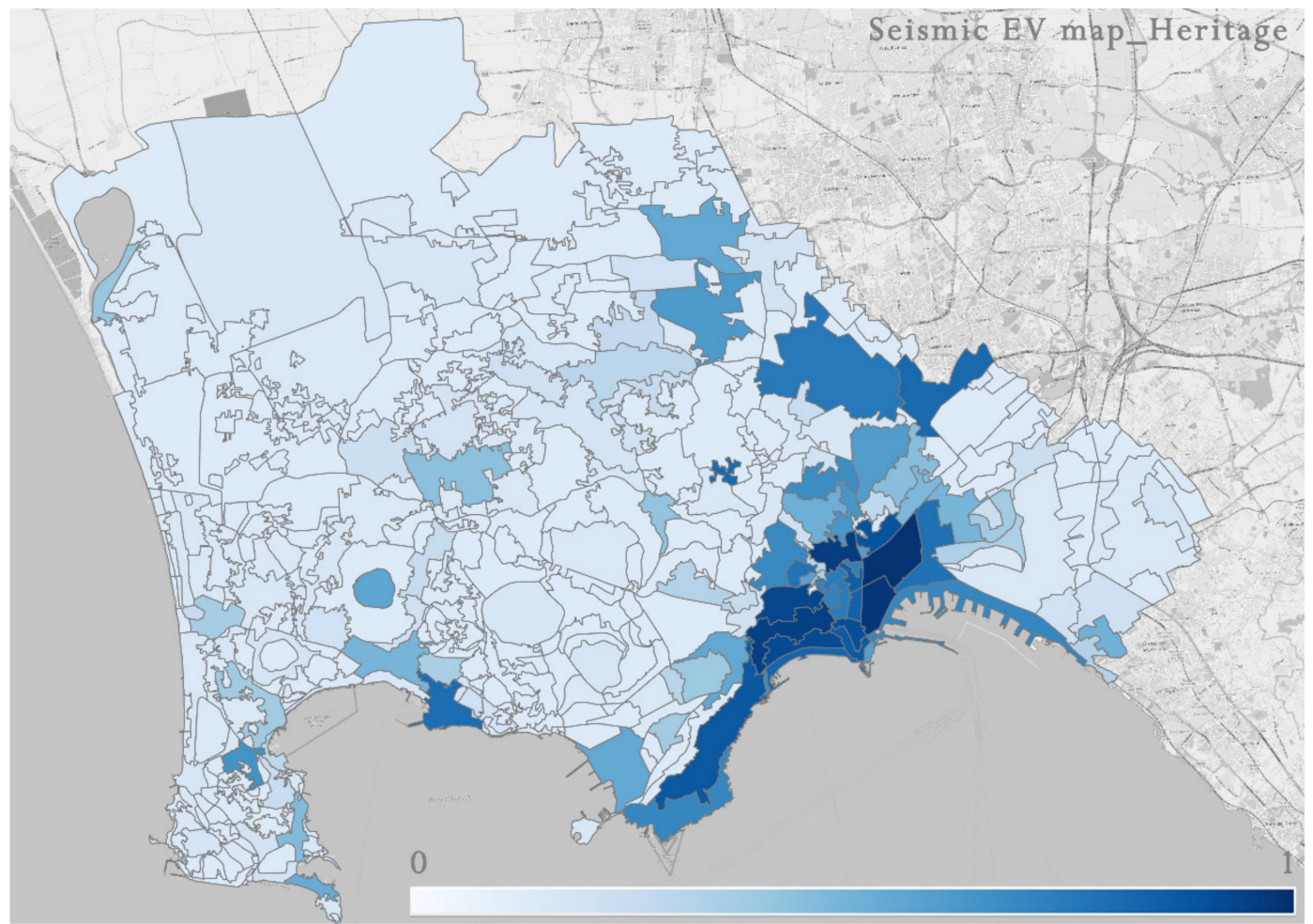

Figure 7. Exposure and vulnerability levels of cultural heritage in the face of earthquakes.

Finally, a summary value of exposure and vulnerability levels of each HSU in respect to all the hazards affecting the case study has been calculated by weighting each vulnerability indicator, according to its relevance in respect to each considered hazard (Table 4) and a comprehensive EV map for the case study area has been carried out (Figure 8).

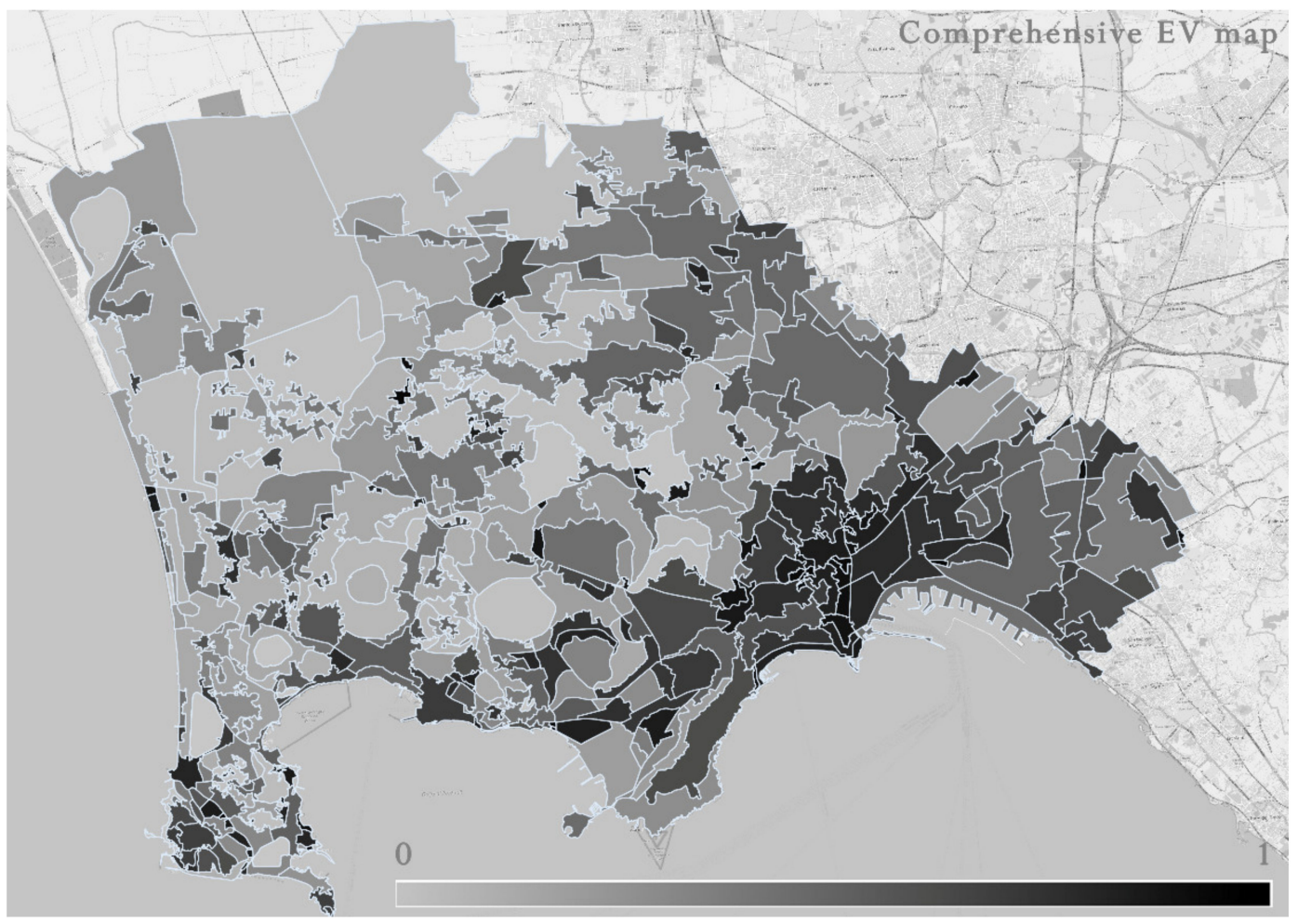

Figure 8. Comprehensive EV map. 
Table 4. Indicators' weight according to the relevance for each hazard.

\begin{tabular}{|c|c|c|c|c|c|c|c|c|}
\hline & \multirow{2}{*}{ Vulnerability Indicators } & \multicolumn{7}{|c|}{$\mathbf{W}$} \\
\hline & & $\mathrm{Eq}$ & LF & $\mathbf{P F}$ & As & La $\quad F 1$ & HW IA & \\
\hline \multirow{12}{*}{$\begin{array}{l}\geq \\
\stackrel{\vec{n}}{\infty} \\
\stackrel{\vec{n}}{a}\end{array}$} & Utilization degree & & & & & & & 0.88 \\
\hline & Urban density & & & & & & & 0.75 \\
\hline & Construction type & & & & & & & 0.13 \\
\hline & Imperviousness & & & & & & & 0.25 \\
\hline & Vegetation index & & & & & & & 0.38 \\
\hline & Conservation degree & & & & & & & 0.50 \\
\hline & Age of buildings & & & & & & & 0.13 \\
\hline & Buildings' material & & & & & & & 0.13 \\
\hline & Number of storeys (height value) & & & & & & & 0.25 \\
\hline & Presence of bridges, tunnels ... & & & & & & & 0.75 \\
\hline & Cultural value & & & & & & & 0.88 \\
\hline & Type of production of industrial sites & & & & & & & 0.88 \\
\hline \multirow{6}{*}{ 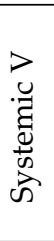 } & Distances of industrial sites from ... & & & & & & & 0.13 \\
\hline & Hierarchical level & & & & & & & 0.88 \\
\hline & Strategic role & & & & & & & 0.88 \\
\hline & Accessibility & & & & & & & 0.88 \\
\hline & Connectivity & & & & & & & 0.88 \\
\hline & Redundancy & & & & & & & 0.88 \\
\hline \multirow{5}{*}{$\begin{array}{l}\geq \\
. \pi \\
0 \\
0 \\
\infty\end{array}$} & Age-old age index & & & & & & & 1.00 \\
\hline & Education & & & & & & & 0.88 \\
\hline & Employment & & & & & & & 0.88 \\
\hline & Autonomy-\% children and elderly & & & & & & & 0.88 \\
\hline & Immigrants and refugees & & & & & & & 0.88 \\
\hline
\end{tabular}

\section{A Focus on Systemic Vulnerability}

As remarked in Section 3, systemic vulnerability indicators require in-depth and tailored-to-the-site analyses of features and roles of urban facilities and transport networks. In the case study area, it has been analysed according to a set of indicators related to:

- Location, redundancy, accessibility, hierarchical levels and role in emergency phase of urban facilities;

- Connectivity and redundancy of road and railway networks.

In particular, the hierarchical level of urban facilities has been defined according to the area served of each facility (regional, municipal, neighbourhood). The same criterion has been applied to the transport networks (e.g., a higher hierarchical level has been attributed to primary roads in respect to secondary and tertiary ones). Moreover, the strategic role of urban facilities has been defined according to their relevance in the emergency phase, in that the maximum value has been assigned to the facilities directly involved in emergency (e.g., hospitals, fire brigades, etc.). All this information can be easily collected from existing spatial plans at provincial/municipal scales as well as by emergency planning tools.

Accessibility levels depend on the relative distances between urban facilities and residential areas. The accessibility indicator refers to each HSU and has been calculated as the minimum physical distance on the road network between each facility and the closest residential areas.

Connectivity represents the degree of connection of each HSU to the primary road and railway networks. Connectivity has been measured through the physical distance of each HSU from the closest junction of the primary road network and the closest railway station and its value increases as the mutual distance decreases.

Redundancy refers to both urban facilities and transport networks. The former takes into account the presence of alternative facilities with a limited increase in travel time. The latter considers the presence of alternative routes to the main one.

According to these indicators, the systemic vulnerability levels in the case study areas have been defined as shown in Figure 9. 


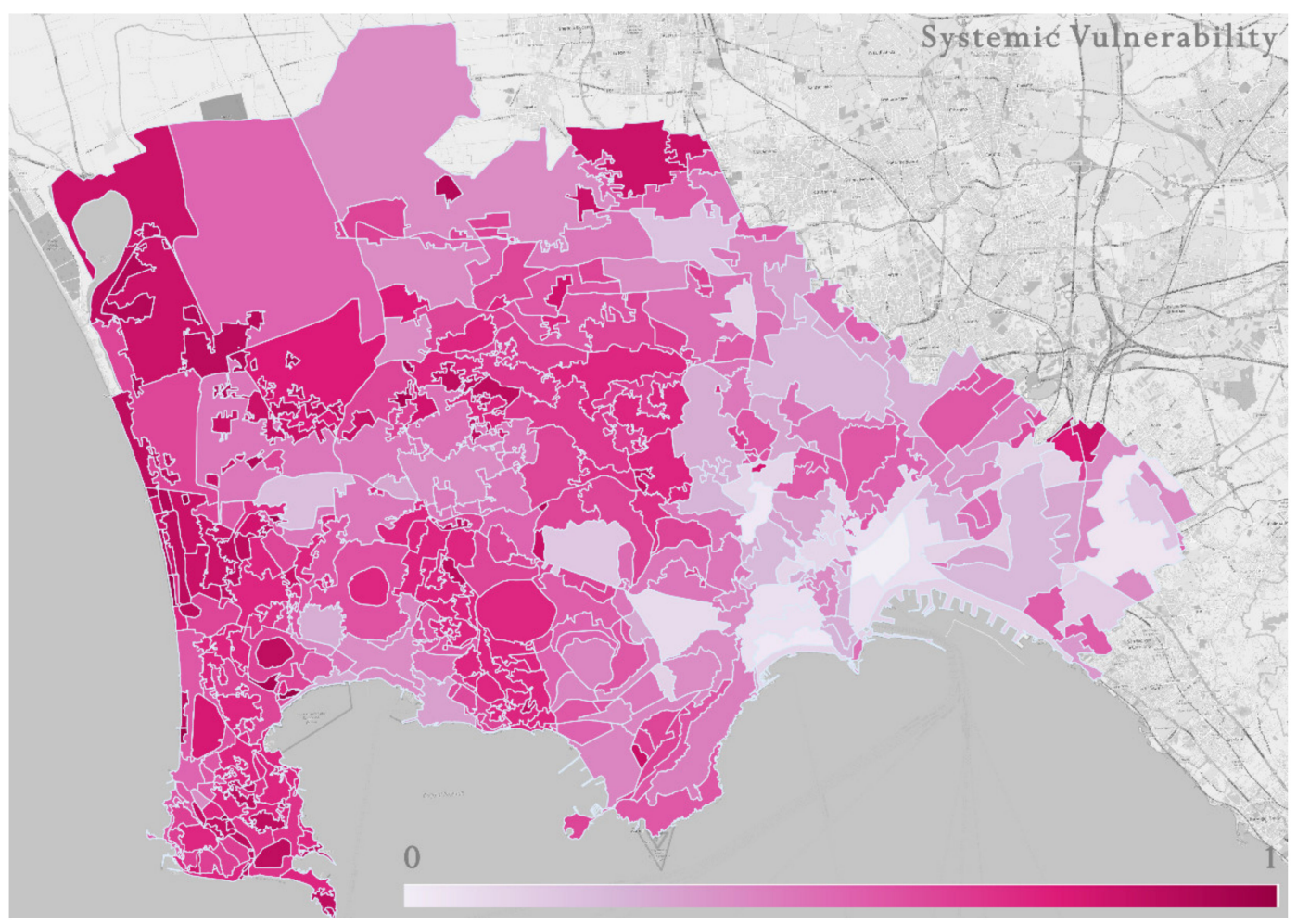

Figure 9. Systemic vulnerability levels.

As remarked in Section 3, the output maps provide different outcomes. In detail, comprehensive EV maps might allow prioritizing, according to a multi-hazard perspective, "hotspot" areas that require urgent measures to reduce exposure/vulnerability. These measures can be then outlined according to the output referred to the single EV maps, to the single classes of exposed elements in respect to individual/multiple hazards. These maps may support, for instance, risk-informed recovery and requalification strategies capable of reducing physical vulnerability of residential areas or cultural heritage in the face of seismic or flood events. It is worth noting that each output map may also allow identifying "thematic hotspot" areas related to the considered topics (e.g., exposure, physical, social, systemic vulnerability). For example, the systemic vulnerability map shows "thematic hotspot" areas, exclusively related to the selected set of systemic vulnerability indicators. These thematic hotspot areas differ from those identified by the Comprehensive EV map (Figure 8) that takes into account all exposure and vulnerability indicators in a multi-hazard perspective.

\section{From Risk Knowledge to Risk-Informed Planning Strategies}

As remarked above, planning strategies aimed at reducing multi-risk levels in urban environments require detailed information on the vulnerabilities of exposed assets and systems $[3,9,10]$ that nowadays are often partially available, largely fragmented and difficult to combine each other. Thus, the outlined methodological path represents a first attempt to overcome the main shortcomings of available risk knowledge and to provide planners with homogeneous and update information on the different risk dimensions. Moreover, the "spatialization" of risk knowledge allows aggregating data and information at different scales: all data and information related to each HSUs can be, in fact, easily scaled up to municipal, provincial or even regional levels. Finally, the adoption of an indicatorbased approach provides planners with a constantly updatable baseline against which the impacts of alternative planning choices on the overall levels of exposure and vulnerabilities as well as on specific risk dimensions (e.g., physical or systemic vulnerability) can be easily measured. 
As remarked in Section 2, nowadays, risk knowledge as well as risk reduction strategies are mostly entrusted to sectoral authorities and tools (e.g., basin authorities, flood management plans), while spatial plans generally collect and assemble available knowledge without developing further analysis, and size their development choices to hints and constraints provided by sectoral plans, without a proper assessment of the impacts of alternative planning choices on current multi-risk levels and, namely, on exposure and vulnerabilities features of the area at stake. To date, while knowledge frameworks that planning tools are based on have been significantly enriched, including data and information related to numerous environmental issues (e.g., consistency and quality of natural resources), they still struggle to effectively embed risk knowledge. Moreover, adequate tools aimed at evaluating the impacts of alternative planning strategies on existing multirisk levels are still often missing. Furthermore, the Strategic Environmental Assessment (SEA), a mandatory tool all over Europe for a wide range of plans and programs, still devotes limited attention to risk issues. While its crucial role in improving environmental protection in the EU has been clearly recognized [49] and numerous scholars have emphasized over time its potential for better integrating risk and more recently climate issues in spatial planning at different scales [50-53], SEA is still mostly focused on the impacts of alternative planning decisions on natural resources with a limited attention to determine whether they are likely to reduce/increase existing multi-risk levels.

Thus, even though the proposed methodology might represent a useful tool to support risk-informed spatial planning strategies, "plan-making" processes should be adequately revised to ensure a proper integration of risk issues in decision-making, with a particular attention to the relationships among sectoral and spatial plans as well as to the improvement of the current tools for plans and programs' evaluation.

In particular, the provided screening tool might be particularly relevant to determine whether urban regeneration policies are likely to have significant effects on existing exposure and vulnerability levels. According to the goals set by the Agenda 2030 and in line with the target of zero soil consumption by 2050, set by the European Commission [54], nowadays, planning processes are mostly oriented to regenerate existing settlements, often located in areas prone to multiple hazards. Hence, in the absence of an adequate multi-risk knowledge base against which the impacts of alternative planning strategies can be measured, and namely of disaggregate information on exposure and vulnerabilities in the face of different hazards, outlined strategies and measures may also result into an increase in current exposure and vulnerability levels in these areas. Moreover, the assessment of the likely impacts of alternative strategies and measures on current multi-risk levels would also contribute to deduct the decisions related to risk reduction from the purely technical domain to which they are generally entrusted and to favor, on the opposite, participatory processes and shared decisions on conflicting planning choices aimed, for example, at improving sustainability through the controversial practices of "densification" [55], which may increase, in turn, exposure and vulnerabilities to existing hazards.

\section{Conclusions}

This contribution provides a first answer, certainly not exhaustive, to the priorities set by the Sendai Framework and namely to the need of improving risk knowledge, by better using already existing knowledge as well as by taking into account all risk components (hazard, exposure and vulnerabilities), in a multi-risk perspective.

In detail, the research work has been addressed to set up a methodological path aimed at developing a comprehensive exposure and vulnerability assessment in multi-hazard urban environments, based on the significant outcomes so far provided by European research projects as well as by scientific literature focused on multi-risk and, above all, on vulnerability assessment. The methodological path has been tested on a case study area, the Phlegraen Fields, a multi-hazard urban area located in the western part of the metropolitan city of Naples, in Southern Italy. 
It is worth underlining that even though all the key steps of the methodological pathhazards' identification and codification, selection of exposure and vulnerability indicators and their codification, normalization and spatialization, criteria for data aggregation to carry out heterogeneous output maps-have to be calibrated from time to time in respect to the geographical area at stake, it may represent a useful guide to better adapt existing risk knowledge to planning needs, allowing the building up of a "flexible" knowledge, capable of guiding and evaluating different planning strategies at different geographical scales. As all data and information are referred to in HSUs, output maps can be carried out in respect to HSUs or to their aggregations in larger units defined by administrative boundaries (e.g., municipalities) or land uses (e.g., urban areas) or hazardous areas (e.g., volcanic zones). Moreover, the different output maps (single EV maps referred to each indicator and to each hazard, EV maps referred to single classes of exposed elements and related to each hazard, comprehensive EV maps) are suitable to inform and assess different planning strategies: from new green corridors at a metropolitan/municipal scale, up to retrofitting interventions at a neighborhood scale. Furthermore, the systemic vulnerability map may represent a relevant guide to identify and strengthen the shortcomings of urban facilities, to support both a more effective emergency management and a better functioning of urban facilities in peace time.

However, the outlined methodological path also reveals some weaknesses: first of all, in order to set up a screening tool easily achievable starting from a "soft" reprocessing of data extracted from existing databases or at least through data elaboration into a GIS environment, some fine-grained indicators that, according to selected scientific literature, might be relevant in respect to specific hazards (e.g., ground-floors' usage, types of roofs) have been neglected, as they require detailed in situ analyses. Furthermore, the relevance of each indicator in respect to each hazard has been defined according to a binary approach (yes/no), which does not highlight the different levels of importance that each indicator may have in respect to each hazard. A more detailed assessment could be performed through specific estimation methods (e.g., multicriteria analysis) that could represent one of the future developments of the research work.

Finally, it is worth noting that the methodological path for a comprehensive exposure and vulnerability assessment represents only a first step towards a comprehensive multirisk assessment. Further steps should devote more attention to the potential interactions among the different hazards that may influence each other, arising complex chains of secondary hazards, impacts and damage. However, the analysis of the mutual influences among hazards and vulnerabilities would require a shift from an indicator-based method to the development of risk scenarios.

Author Contributions: Conceptualization, A.G.; methodology, G.L.; writing Sections 1, 2, 5 and 6, A.G.; writing Sections 3 and 4, G.L.; review, A.G.; editing, G.L.; supervision, A.G. Both authors have read and agreed to the published version of the manuscript.

Funding: This research received no external funding.

Institutional Review Board Statement: Not applicable.

Informed Consent Statement: Not applicable.

Data Availability Statement: All data used in this study comes from public datasets. National Census on population and housing (https://www.istat.it/en/); Copernicus CORINE Land Cover ( https://land.copernicus.eu/pan-european/corine-land-cover); Copernicus High Resolution Layers (https://land.copernicus.eu/pan-european/high-resolution-layers); Cultural Heritage database "Vincoli in Rete" (http:/ /vincoliinrete.beniculturali.it/VincoliInRete/vir/utente/login); Regional register of hazardous industrial sites (https:/ / www.arpacampania.it/arir).

Conflicts of Interest: The authors declare no conflict of interest. 


\section{References}

1. Kappes, M.S.; Gruber, K.; Frigerio, S.; Bell, R.; Keiler, M.; Glade, T. The MultiRISK platform: The technical concept and application of a regional-scale multihazard exposure analysis tool. Geomorphology 2012, 151-152, 139-155. [CrossRef]

2. Komendantova, N.; Scolobig, A.; Garcia-Aristizabal, A.; Monfort, D.; Fleming, K. Multi-risk approach and urban resilience. Int. J. Disaster Resil. Built Environ. 2016, 7, 114-132. [CrossRef]

3. Scolobig, A.; Komendantova, N.; Mignan, A. Mainstreaming Multi-Risk Approaches into Policy. Geosciences 2017, 7, 129. [CrossRef]

4. De Ruiter, M.C.; Couasnon, A.; Homberg, M.J.V.D.; Daniell, J.E.; Gill, J.C.; Ward, P.J. Why We Can No Longer Ignore Consecutive Disasters. Earth's Future 2020, 8. [CrossRef]

5. Carpignano, A.; Golia, E.; Di Mauro, C.; Bouchon, S.; Nordvik, J.P. A methodological approach for the definition of multi-risk maps at regional level: First application. J. Risk Res. 2009, 12, 513-534. [CrossRef]

6. Kappes, M.S.; Keiler, M.; von Elverfeldt, K.; Glade, T. Challenges of analyzing multi-hazard risk: A review. Nat. Hazards 2012, 64, 1925-1958. [CrossRef]

7. Gasparini, P.; Garcia-Aristizabal, A. Seismic Risk Assessment, Cascading Effects. In Encyclopedia of Earthquake Engineering; Beer, M., Kougioumtzoglou, I., Patelli, E., Au, S., Eds.; Springer: Berlin/Heidelberg, Germany, 2015; pp. 3004-3022.

8. Graff, K.; Lissak, C.; Thiery, Y.; Maquaire, O.; Costa, S.; Medjkane, M.; Laignel, B. Characterization of elements at risk in the multirisk coastal context and at different spatial scales: Multi-database integration (normandy, France). Appl. Geogr. 2019, 111, 102076. [CrossRef]

9. UNISDR. Sendai Framework for Disaster Risk Reduction 2015-2030; UNISDR: Geneva, Switzerland, 2015.

10. Galderisi, A.; Limongi, G. Improving Risk Knowledge for Planning Purposes: Critical Issues and Hints for Enhancement. In New Metropolitan Perspectives Knowledge Dynamics and Innovation-Driven Policies towards Urban and Regional Transition; Bevilacqua, C., Francesco, C., Della Spina, L., Eds.; Springer Nature: Cham, Switzerland, 2020; pp. 606-617. ISBN 978-3-030-48279-4.

11. Månsson, P. Uncommon sense: A review of challenges and opportunities for aggregating disaster risk information. Int. J. Disaster Risk Reduct. 2019, 40, 101149. [CrossRef]

12. White, G.F.; Kates, R.W.; Burton, I. Knowing better and losing even more: The use of knowledge in hazards management. Environ. Hazards 2001, 3, 81-92. [CrossRef]

13. Wang, J.; He, Z.; Weng, W. A review of the research into the relations between hazards in multi-hazard risk analysis. Nat. Hazards 2020, 104, 2003-2026. [CrossRef]

14. Curt, C. Multirisk: What trends in recent works?-A bibliometric analysis. Sci. Total Environ. 2021, 763, 142951. [CrossRef] [PubMed]

15. Gallina, V.; Torresan, S.; Critto, A.; Sperotto, A.; Glade, T.; Marcomini, A. A review of multi-risk methodologies for natural hazards: Consequences and challenges for a climate change impact assessment. J. Environ. Manag. 2016, 168, 123-132. [CrossRef] [PubMed]

16. Marzocchi, W.; Garcia-Aristizabal, A.; Giardini, P.; Mastellone, M.; Di Ruocco, A. Basic principles of multi-risk assessment: A case study in Italy. Nat. Hazards 2012, 62, 551-573. [CrossRef]

17. Mignan, A.; Wiemer, S.; Giardini, D. The quantification of low-probability-high-consequences events: Part I. A generic multi-risk approach. Nat. Hazards 2014, 73, 1999-2022. [CrossRef]

18. Papathoma-Köhle, M.; Kappes, M.; Keiler, M.; Glade, T. Physical vulnerability assessment for alpine hazards: State of the art and future needs. Nat. Hazards 2011, 58, 645-680. [CrossRef]

19. Kappes, M.S.; Papathoma-Köhle, M.; Keiler, M. Assessing physical vulnerability for multi-hazards using an indicator-based methodology. Appl. Geogr. 2012, 32, 577-590. [CrossRef]

20. Papathoma-Köhle, M.; Cristofari, G.; Wenk, M.; Fuchs, S. The importance of indicator weights for vulnerability indices and implications for decision making in disaster management. Int. J. Disaster Risk Reduct. 2019, 36, 101103. [CrossRef]

21. Julià, P.B.; Ferreira, T.M. From single- to multi-hazard vulnerability and risk in Historic Urban Areas: A literature review. Nat. Hazards 2021, 108, 93-128. [CrossRef]

22. Gallina, V.; Torresan, S.; Zabeo, A.; Critto, A.; Glade, T.; Marcomini, A. A multi-risk methodology for the assessment of climate change impacts in coastal zones. Sustainability 2020, 12, 3697. [CrossRef]

23. Limongi, G.; Galderisi, A. Twenty years of European research on vulnerability: A multi-faceted concept for better dealing with evolving risk landscapes. Int. J. Disaster Risk Reduct. 2021, 63, 102451. [CrossRef]

24. Ivčević, A.; Mazurek, H.; Siame, L.; Ben Moussa, A.; Bellier, O. Indicators in risk management: Are they a user-friendly interface between natural hazards and societal responses? Challenges and opportunities after UN Sendai conference in 2015. Int. J. Disaster Risk Reduct. 2019, 41, 101301. [CrossRef]

25. Cutter, S.L. Vulnerability. In Encyclopedia of Natural Hazards; Springer: Dordrecht, The Netherlands, 2013 ; p. 1090.

26. UN Secretary-General. Report of the open-ended intergovernmental expert working group on indicators and terminology relating to disaster risk reduction. In Proceedings of the Seventy-First Session Agenda Item 19 (c) Sustainable Development: Disaster Risk Reduction, New York, NY, USA, 1 December 2016.

27. Papathoma-Köhle, M.; Gems, B.; Sturm, M.; Fuchs, S. Matrices, curves and indicators: A review of approaches to assess physical vulnerability to debris flows. Earth Sci. Rev. 2017, 171, 272-288. [CrossRef] 
28. Birkmann, J. Measuring Vulnerability to Natural Hazards: Towards Disaster Resilient Societies, 2nd ed.; United Nation University Press: Tokyo, Japan, 2013.

29. Birkmann, J. Data, indicators and criteria for measuring vulnerability: Theoretical bases and requirements. In Measuring Vulnerability to Natural Hazards: Towards Disaster Resilient Societies, 2nd ed.; United Nation University Press: Tokyo, Japan, 2013.

30. Rufat, S.; Tate, E.; Burton, C.G.; Maroof, A.S. Social vulnerability to floods: Review of case studies and implications for measurement. Int. J. Disaster Risk Reduct. 2015, 14, 470-486. [CrossRef]

31. Cho, S.Y.; Chang, H. Recent research approaches to urban flood vulnerability, 2006-2016. Nat. Hazards 2017, 88, 633-649. [CrossRef]

32. Contreras, D.; Chamorro, A.; Wilkinson, S. Review article: The spatial dimension in the assessment of urban socio-economic vulnerability related to geohazards. Nat. Hazards Earth Syst. Sci. 2020, 20, 1663-1687. [CrossRef]

33. Tallman, P.S.; Valdés-Velásquez, A.; Salmón-Mulanovich, G.; Lee, G.O.; Riley-Powell, A.R.; Blanco-Villafuerte, L.; Hartinger, S.M.; Paz-Soldán, V.A. A “Cookbook” for Vulnerability Research. Front. Public Health 2019, 7, 352. [CrossRef] [PubMed]

34. Barbat, A.H.; Carreño, M.L.; Pujades, L.G.; Lantada, N.; Cardona, O.D.; Marulanda, M.C. Seismic vulnerability and risk evaluation methods for urban areas. A review with application to a pilot area. Struct. Infrastruct. Eng. 2010, 6, 17-38. [CrossRef]

35. Rufat, S.; Tate, E.; Emrich, C.T.; Antolini, F. How Valid Are Social Vulnerability Models? Ann. Am. Assoc. Geogr. 2019, 109, 1131-1153. [CrossRef]

36. Sapountzaki, K.; Dandoulaki, M.; Wassenhoven, L.; Melissourgos, Y.; Vikatou, K.; Galderisi, A.; Parker, D.; Handmer, J.; Menoni, S. State-of-the-Art on Vulnerability of Territorial Systems. The Case of Hydro-Geological Hazards; Report Number: Del. 1.1.2-1, EC Contract No. 212046; Technical Report for ENSURE Project: Bruseels, Belgium, 2009.

37. Pascale, S.; Sdao, F.; Sole, A. A model for assessing the systemic vulnerability in landslide prone areas. Nat. Hazards Earth Syst. Sci. 2010, 10, 1575-1590. [CrossRef]

38. Minciardi, R.; Sacile, R.; Taramasso, A.C.; Trasforini, E.; Traverso, S. Modeling the vulnerability of complex territorial systems: An application to hydrological risk. Environ. Model. Softw. 2006, 21, 949-960. [CrossRef]

39. Galderisi, A.; Bonadonna, C.; Delmonaco, G.; Ferrara, F.F.; Menoni, S.; Ceudech, A.; Biass, S.; Frischknecht, C.; Manzella, I.; Minucci, G.; et al. Vulnerability assessment and risk mitigation: The case of Vulcano Island, Italy. In Landslide Science and Practice: Social and Economic Impact and Policies; Springer: Berlin/Heidelberg, Germany, 2013; Volume 7, pp. 55-64.

40. Scaini, C.; Biass, S.; Galderisi, A.; Bonadonna, C.; Folch, A.; Smith, K.; Höskuldsson, A. A multi-scale risk assessment for tephra fallout and airborne concentration from multiple Icelandic volcanoes-Part 2: Vulnerability and impact. Nat. Hazards Earth Syst. Sci. 2014, 14, 2289-2312. [CrossRef]

41. Aliabadi, S.F.; Sarsangi, A.; Modiri, E. The social and physical vulnerability assessment of old texture against earthquake (case study: Fahadan district in Yazd City). Arab. J. Geosci. 2015, 8, 10775-10787. [CrossRef]

42. Elboshy, B.; Kanae, S.; Gamaleldin, M.; Ayad, H.; Osaragi, T.; Elbarki, W. A framework for pluvial flood risk assessment in Alexandria considering the coping capacity. Environ. Syst. Decis. 2019, 39, 77-94. [CrossRef]

43. Cacace, F.; Zuccaro, G.; De Gregorio, D.; Perelli, F.L. Building Inventory at National scale by evaluation of seismic vulnerability classes distribution based on Census data analysis: BINC procedure. Int. J. Disaster Risk Reduct. 2018, 28, 384-393. [CrossRef]

44. Maragno, D.; Dall'omo, C.F.; Pozzer, G.; Musco, F. Multi-risk climate mapping for the adaptation of the venice metropolitan area. Sustainability 2021, 13, 1334. [CrossRef]

45. Cutter, S.L.; Barnes, L.; Berry, M.; Burton, C.; Evans, E.; Tate, E.; Webb, J. A place-based model for understanding community resilience to natural disasters. Glob. Environ. Chang. 2008, 18, 598-606. [CrossRef]

46. Tilio, L.; Murgante, B.; Di Trani, F.; Vona, M.; Masi, A. Mitigation of urban vulnerability through a spatial multicriteria approach. Disaster Adv. 2012, 5, 138-143.

47. Khademi, N.; Balaei, B.; Shahri, M.; Mirzaei, M.; Sarrafi, B.; Zahabiun, M.; Mohaymany, A.S. Transportation network vulnerability analysis for the case of a catastrophic earthquake. Int. J. Disaster Risk Reduct. 2015, 12, 234-254. [CrossRef]

48. Galderisi, A.; Guida, G.; Limongi, G. Emergency and spatial planning towards cooperative approaches. Challenges and opportunities in the multi-risk area of Campi Flegrei. TeMA J. Land Use Mobil. Environ. 2021, 73-92. [CrossRef]

49. European Commission. Commission Staff Working Document Evaluation of the Directive 2001/42/EC on the Assessment of the Effects of Certain Plans and Programmes on the Environment; European Commission: Brussels, Belgium, 2019.

50. Greiving, S. Risk Assessment and Management as an Important Tool for the EU Strategic Environmental Assessment. disP Plan. Rev. 2004, 40, 11-17. [CrossRef]

51. Galderisi, A.; Profice, A.S. Sustainability, risks, land use planning: Tools for integration. WIT Trans. Ecol. Environ. 2012, 155, 981-992.

52. Susilowardhani, A. The potential of strategic environmental assessment to address the challenges of climate change to reduce the risks of disasters: A case study from Semarang. Procedia Soc. Behav. Sci. 2014, 135, 3-9. [CrossRef]

53. Islam, M.S.; Zhang, Y. The potential of strategic environmental assessment to reduce disaster risks through climate change adaptation in the coastal zone of Bangladesh. Int. J. Clim. Chang. Strateg. Manag. 2019, 11, 137-153. [CrossRef]

54. Solly, A.; Berisha, E.; Cotella, G.; Janin-Rivolin, U. How Sustainable Are Land Use Tools? A Europe-Wide Typological Investigation. Sustainability 2020, 12, 1257. [CrossRef]

55. Conticelli, E.; De Luca, C.; Tondelli, S. Assessing the balance between urban development and densification. BDC Boll. del Cent. Calza Bini Univ. degli Stud. di Napoli Federico II 2020, 20, 231-240. 